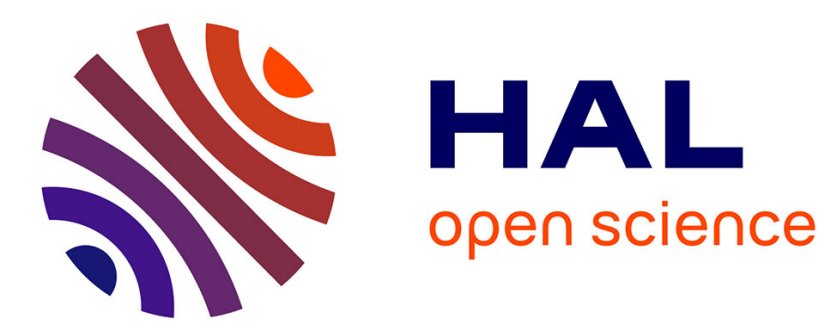

\title{
Interrelationships between thermomechanical treatment and macromolecular degradation of maize starch in a novel rheometer with preshearing
}

\author{
Bruno Vergnes, J.P. Villemaire, Paul Colonna, J. Tayeb
}

\section{To cite this version:}

Bruno Vergnes, J.P. Villemaire, Paul Colonna, J. Tayeb. Interrelationships between thermomechanical treatment and macromolecular degradation of maize starch in a novel rheometer with preshearing. Journal of Cereal Science, 1987, 5, pp.189-202. hal-02722967

\section{HAL Id: hal-02722967 \\ https://hal.inrae.fr/hal-02722967}

Submitted on 1 Jun 2020

HAL is a multi-disciplinary open access archive for the deposit and dissemination of scientific research documents, whether they are published or not. The documents may come from teaching and research institutions in France or abroad, or from public or private research centers.
L'archive ouverte pluridisciplinaire HAL, est destinée au dépôt et à la diffusion de documents scientifiques de niveau recherche, publiés ou non, émanant des établissements d'enseignement et de recherche français ou étrangers, des laboratoires publics ou privés. 


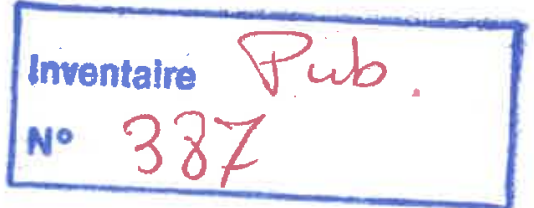

\title{
Interrelationships between Thermomechanical Treatment and Macromolecular Degradation of Maize Starch in a Novel Rheometer with Preshearing
}

\author{
B. VERGNES*†, J. P. VILLEMAIRE*, P. COLONNA $\ddagger$ and J. TAYEB $\ddagger$ \\ * Centre de Mise en Forme des Matériaux, U.A.CNRS 852, Ecole des Mines de Paris, \\ Sophia-Antipolis, 06565 Valbonne, France $\ddagger$ Institut National de la Recherche \\ Agronomique, Centre de Recherches Agro-alimentaires, \\ 44072 Nantes, France
}

Received 17 March 1986

\begin{abstract}
Using a newly developed rheometer with preshearing, maize starch was subjected to several thermomechanical treatments that involved varying temperature $\left(140-180^{\circ} \mathrm{C}\right)$, rotation rate $(200-700 \mathrm{r} / \mathrm{min})$ and processing time $(5-40 \mathrm{~s})$. Processed starches lost their native A-type crystalline structure to yield typical $\mathrm{E}$ - and $V$-structures. The degree of macromolecular degradation, expansion and water solubility were determined for the different products. The results indicated that these products are similar to those obtained from extrusion-cooking. By computing the melting and shearing process of starch in the rheometer, the quantity of energy imparted to the sample was evaluated and correlated to intensity of thermomechanical treatment. An interrelationship between degree of macromolecular degradation and intensity of treatment has been clearly established; intrinsic viscosity decreased with increasing thermomechanical energy input, whereas the water solubility index increased.
\end{abstract}

\section{Introduction}

The effects of extrusion-cooking on starch have been widely studied during the last ten years $^{1,2}$. The main effects of this thermomechanical treatment are: 1 , to disrupt granule structure and depolymerise starch components ${ }^{3} ; 2$, to partly gelatinise starch granules and 3 , partly or completely to destroy the native crystalline-like structure ${ }^{4,5}$. In the presence of fatty acids or monoglycerides, an organised structure of helical lipid-amylose complexes appears, which is similar to the $n$-butanol amylose V-complex ${ }^{5,6}$. Extrusioncooking modifies both the water solubility and the water absorption capacity of the starch prior to rheological measurement ${ }^{7-13}$. Amylose and amylopectin are degraded into lower molecular weight materials by purely random chain scission ${ }^{3,5,6,14,18}$. Increased process intensity, which occurs with higher temperature or higher screw speed or lower moisture content, leads to higher levels of starch modification. However, the term 'intensity' is very imprecise. Response surface analysis helps to visualize relationships

Abbreviation used: GPC = gel permeation chromatography.

$\dagger$ To whom correspondence should be addressed.

$0733-5210 / 87 / 020189+14 \$ 03.00 / 0$

(C) 1987 Academic Press Inc. (London) Limited 
between a product characteristic and process parameters ${ }^{19,20}$. However, such regression models have no use in scaling up: mechanistic models have to be developed, correlating changes within the extruded product as a function of extrusion parameters (shear and temperature profiles, residence time, etc).

In conventional single or twin-screw extruders, the shear rates, temperatures and residence times are very heterogeneous and difficult to measure ${ }^{17}$. In order to study the specific influence of these parameters, a newly developed instrument, called the ' $R$ heoplast', was used. It is a capillary rheometer with the facility to apply a well-defined preshearing. It was designed and built to study the rheology of thermoplastic polymers (polyethylene, polystyrene, polyvinyl chloride etc.), by processing raw materials under similar conditions (shear, temperature, processing time) to those known to occur in extruders ${ }^{21,22}$.

The purpose of this paper is to correlate the degree of starch degradation with the quantity of mechanical energy received by the sample during the treatment in the Rheoplast. The concept of intensity will be quantified in terms of thermomechanical parameters involved in the process.

\section{Material and Methods}

\section{Starch sample}

A commercial maize starch (Roquette Frères, Lestrem, France) was processed in the Rheoplast at a moisture content of $22 \%$.

\section{Processing}

The Rheoplast (Fig. 1) combines the features of a Couette rotational system (to execute the melting) and a capillary viscometer (to measure the viscosity). Stareh granules are drawn from the hopper (1) into the cylindrical shearing chamber (5) by the movement of the annular piston (2). The piston (3) begins to rotate and creates a shear field in the gap between the barrel (4) and the piston (3). Here the starch is melted, both by mechanical shearing and by heat conduction from the thermostated barrel. After a predetermined time, the rotation is stopped and the piston (3) is moved up to open a clearance at the bottom of the shearing chamber. Due to gravity and the pressure imposed by the annular piston (2), the melted material is then transferred to the injection pot (6). The volume of the injection pot is identical with that of the shearing chamber, so that one batch is sufficient to fill the injection pot totally. Then, the piston (3) is moved down and the material is pushed through the capillary (8). The viscosity is determined by measuring the pressure (transducer (7)) and the output rate (piston speed). The processed sample is collected at the capillary exit for subsequent analysis. The main advantage of the Rheoplast is that it is capable of subjecting the material to a well characterised thermomechanical treatment.

The shear rate is determined by the rotation rate $(\Omega)$ of the inner piston (3). The shear rate can be considered as quasi-uniform because of the thickness of the melting zone (barrel diameter, $21 \mathrm{~mm}$; inner piston diameter, $16 \mathrm{~mm}$; melting zone thickness, $2.5 \mathrm{~mm}$; melting zone length, $6 \mathrm{~cm}$ ). For this study the rotation rates were 200,400 or $700 \mathrm{r} / \mathrm{min}$, which correspond to mean shear rates between 75 and $250 / \mathrm{s}$.

The melt temperature is controlled by the circulation of a thermostated fluid through channels around the barrel. It is measured by a thermocouple (9) located in the injection pot. The temperature was set at 140,160 and $180^{\circ} \mathrm{C}$.

The shearing time is the time for which the inner piston is rotated and which, for this study, were $5,10,20$ and $40 \mathrm{~s}$. 


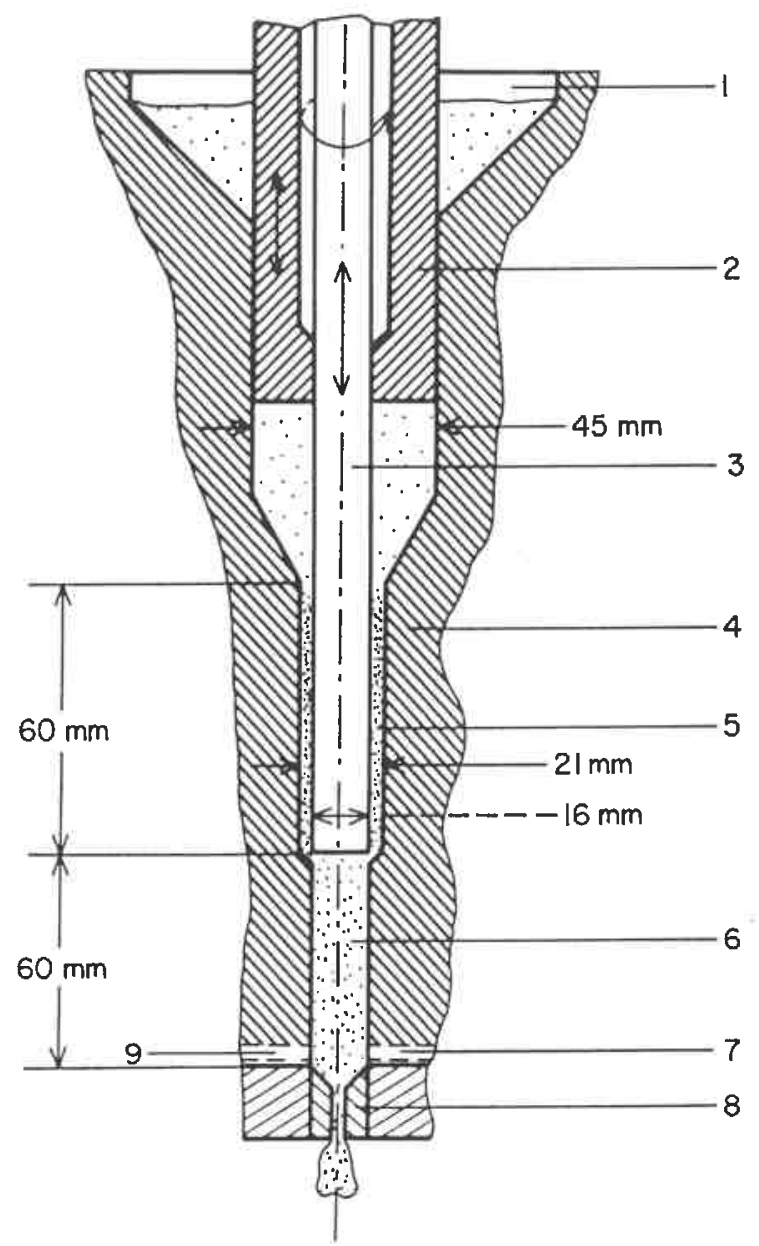

FIGURE 1. Diagram of the Rheoplast. 1, Hopper; 2, annular piston; 3, inner piston; 4 , barrel; 5 , shearing chamber; 6 , injection pot; 7 , pressure transducer; 8 , capillary; 9 , thermocouple.

After the thermomechanical treatment, the processed starch is pushed by the inner piston through a capillary (diameter, $3 \mathrm{~mm}$; length, $12.5 \mathrm{~mm}$ ) at a constant speed of $1 \mathrm{~cm} / \mathrm{s}$. The shear in the capillary is the same for all the treatments and is negligible in comparison with the shear received in the Couette zone (5).

\section{Analytical methods}

The modification of the physical structure of starch was studied using X-ray diffraction ${ }^{6}$ and scanning electron microscopy ${ }^{5}$.

The macromolecular degradation of processed samples was followed by the measurement of intrinsic viscosity and elution profiles using gel permeation chromatography (GPC) ${ }^{15}$. Intrinsic viscosity $[\eta]$ of extruded products was determined at $25^{\circ} \mathrm{C}$ with an automatic Ubbelohde viscometer (solvent flow time, $366 \mathrm{~s}$ ). Dimethylsulphoxide (DMSO) was used as a solvent using concentrations in the range of $0.5-4.0 \mathrm{mg} / \mathrm{ml}$. For each sample, five concentrations were used. Intrinsic viscosity values were measured with very good precision (relative error of 1 or $2 \%$ ). Gel permeation chromatography was performed on a column of hydrophilic vinyl polymer (HW 75, Merck), eluted with $0.1 \mathrm{M} \mathrm{KOH}$, as described previously ${ }^{23}$. Each fraction of the chromatogram was identified by its partition coefficient $K_{\mathrm{av}}$, where $K_{\mathrm{av}}=\left(V_{e}-V_{0}\right) /\left(V_{t}-V_{0}\right) ; V_{e}, V_{t}$ and $V_{0}$ are the fraction elution volume, exclusion volume (as native amylopectin elution volume) and total 
volume (as glucose elution volume), respectively. Each fraction was characterised by determining the $\lambda_{\max }$ of its iodine complex ${ }^{23}$.

Two functional properties of the processed samples were studied: water solubility ${ }^{18}$ and expansion of extruded products (the expansion is expressed as the ratio between the cross-sectional area of the rod shaped product and the area of the die). For each sample, three measurements were carried out to determine the water solubility. The final value was usually obtained with a relative error of less than $5 \%$.

\section{Results}

Starch samples processed in the Rheoplast were characterised using the same range of experimental methods for extruded starches as in previous work ${ }^{3,15}$. After processing, all the samples presented a ropelike structure, more or less expanded in which the initial granular morphology had been lost.

\section{Crystalline modifications}

X-ray powder diffraction of native maize starch yields an A-type pattern (Fig. 2). This pattern disappeared when the starch was processed in the Rheoplast. Under mild

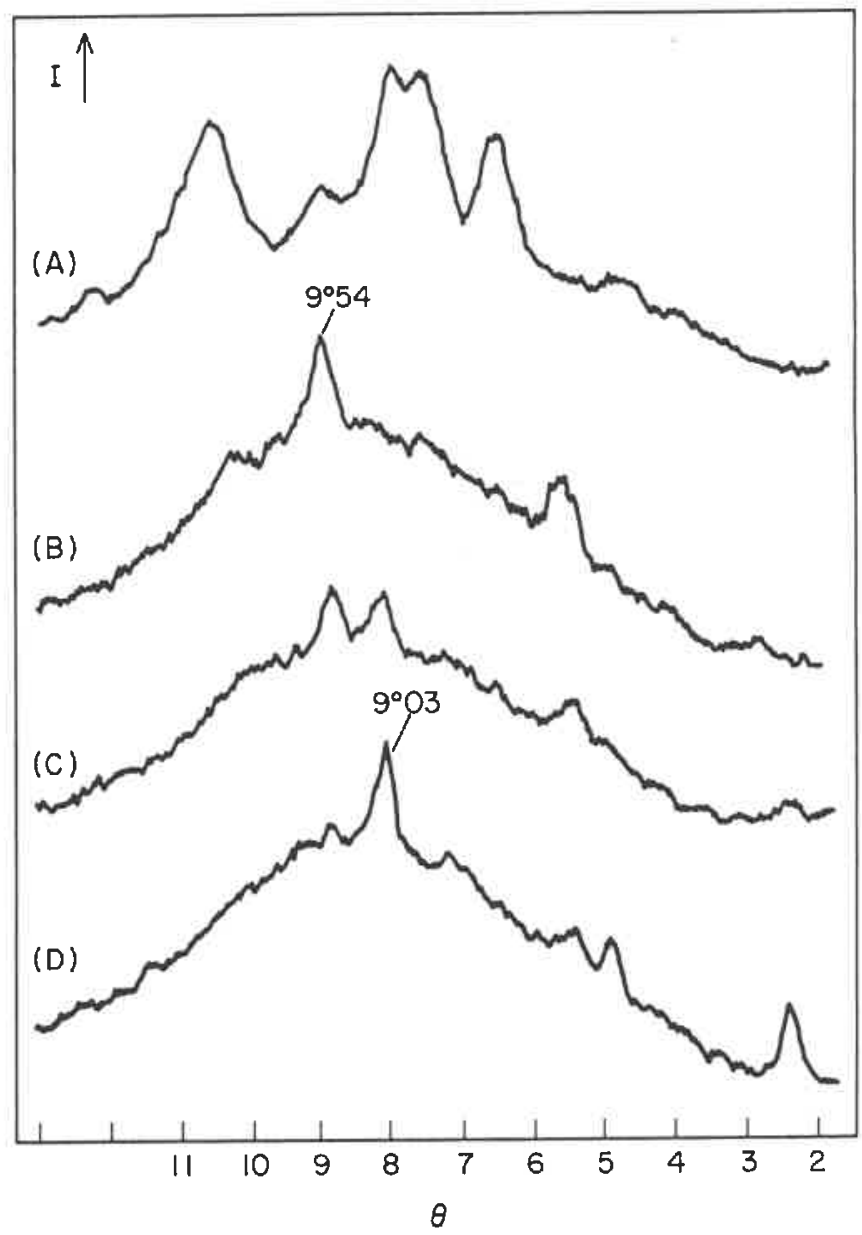

FIGURE 2. X-ray spectra of maize starches, native (A) and processed in the Rheoplast under different conditions, $140^{\circ} \mathrm{C}, 200 \mathrm{r} / \mathrm{min}$ for $20 \mathrm{~s}(\mathrm{~B}) ; 180^{\circ} \mathrm{C}$, $200 \mathrm{r} / \mathrm{min}$ for $20 \mathrm{~s}(\mathrm{C}) ; 140^{\circ} \mathrm{C}, 400 \mathrm{r} / \mathrm{min}$ for $20 \mathrm{~s}(\mathrm{D})$. 
conditions (i.e. $140^{\circ} \mathrm{C}, 200 \mathrm{r} / \mathrm{min}, 20 \mathrm{~s}$ ), a new pattern appeared (Fig. 2). It is composed of three diffraction peaks, with the major one at $9^{\circ} 54^{\prime}$. This spectrum corresponds to the V-amylose structure ${ }^{5}$. When starch was processed more intensely $\left(140^{\circ} \mathrm{C}, 400 \mathrm{r} / \mathrm{min}\right.$, $20 \mathrm{~s}$ ), the sample exhibited a pattern characteristic of E-type structure with its main diffraction peak at $9^{\circ} 03^{\prime}$ (slightly different from the V-type) ${ }^{5}$. Under intermediate processing conditions $\left(180^{\circ} \mathrm{C}, 200 \mathrm{r} / \mathrm{min}, 20 \mathrm{~s}\right)$, both $\mathrm{E}$ - and V-type structures were present (Fig. 2).

\section{Molecular modifications}

In GPC, macromolecules are eluted in the reverse order of their hydrodynamic volume, i.e. the largest molecules being eluted first. The elution curve of native maize starch was characterised by two peaks, located, respectively, at $K_{\mathrm{av}}=0$ and $K_{\mathrm{av}}=0.8$ (Fig. 3). The first, representing $66 \%$ of the total polysaccharides, had a maximum absorption of its iodine complex $\left(\lambda_{\max }\right)$ at a wavelength of $540 \mathrm{~nm}$, specific for amylopectin ${ }^{23}$. The

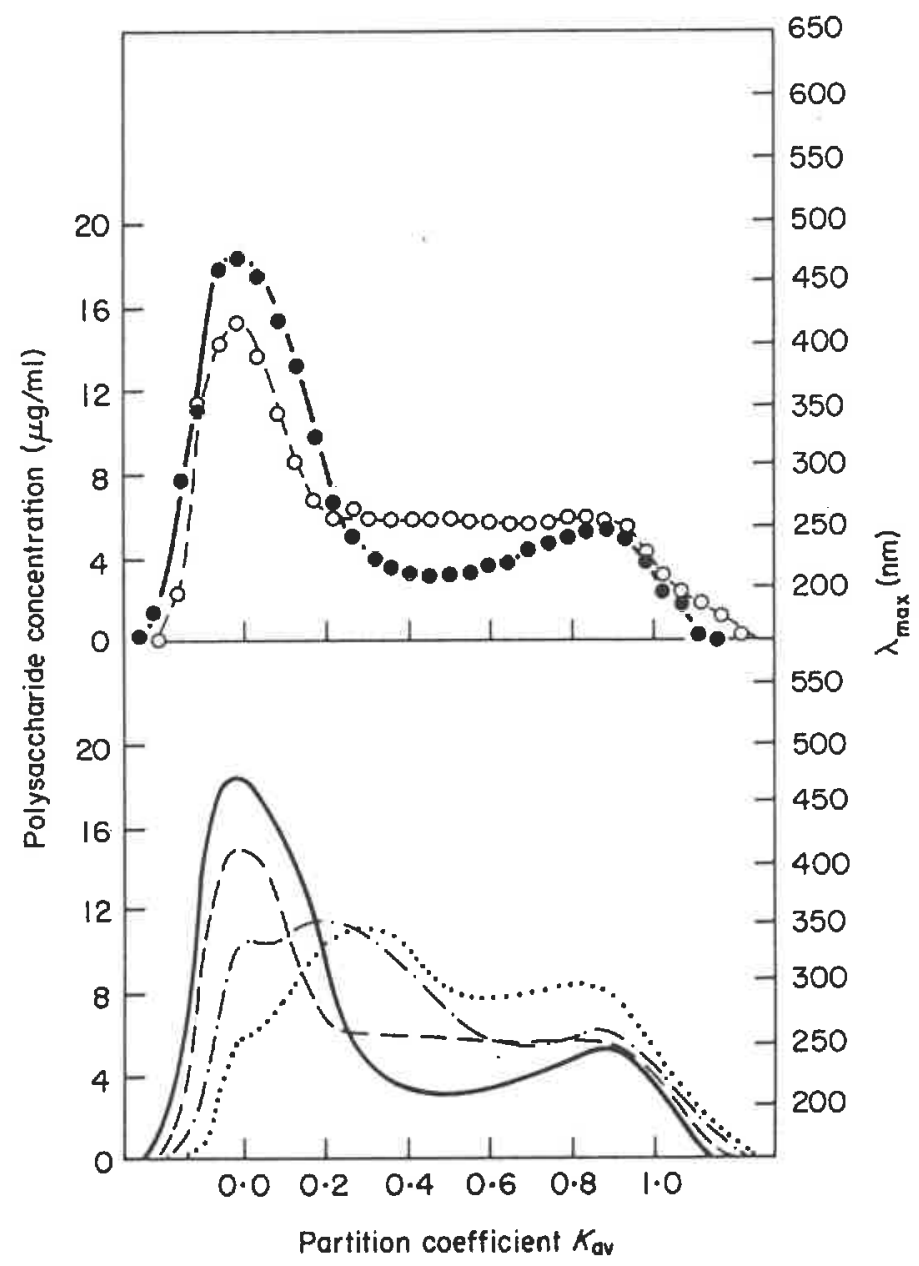

FIGURE 3. Elution profiles of maize starches from GPC on HW 75. The figure shows polysaccharide concentrations in fractions from native $(\bullet)$ and processed $(0)$ starches: $140^{\circ} \mathrm{C}, 100 \mathrm{r} / \mathrm{min}$ for $60 \mathrm{~s},-\longrightarrow ; 180^{\circ} \mathrm{C}, 200 \mathrm{r} / \mathrm{min}$ for $20 \mathrm{~s}, \ldots .-; 140^{\circ} \mathrm{C}$, $400 \mathrm{r} / \mathrm{min}$ for $40 \mathrm{~s}, \ldots \ldots \lambda_{\max }$ values of iodine complexes are also shown. 
second peak had maximum absorption at $620 \mathrm{~nm}$, specific for amylose ${ }^{23}$. The variation of $\lambda_{\max }$ with elution volume reflects an increasing contamination of amylopectin with amylose, pure amylose being observed only after $K_{\mathrm{av}}=0.71$. After processing, the relative amount of excluded material at the void volume decreased (to $16.3 \%$ for $140{ }^{\circ} \mathrm{C}$, $400 \mathrm{r} / \mathrm{min} 40 \mathrm{~s}$ ). Concurrently, $\lambda_{\max }$ values of iodine complexes indicate that amylopectin was present at $K_{\mathrm{av}}=0 \cdot 77$. The same behaviour was observed for amylose. The profiles obtained by GPC demonstrate clearly that the processing by the Rheoplast induced degradation of amylose and amylopectin; the degree of depolymerisation is a function of the intensity of the treatment.

The intrinsic viscosity of native maize starch was $210 \mathrm{ml} / \mathrm{g}$ in pure dimethylsulphoxide. After processing, the intrinsic viscosity was always reduced $(30-45 \%)$ which confirms that macromolecular degradation had occurred. It decreased with increasing rotation time (Fig. 4) and rotation rate and was further lowered by high temperatures.

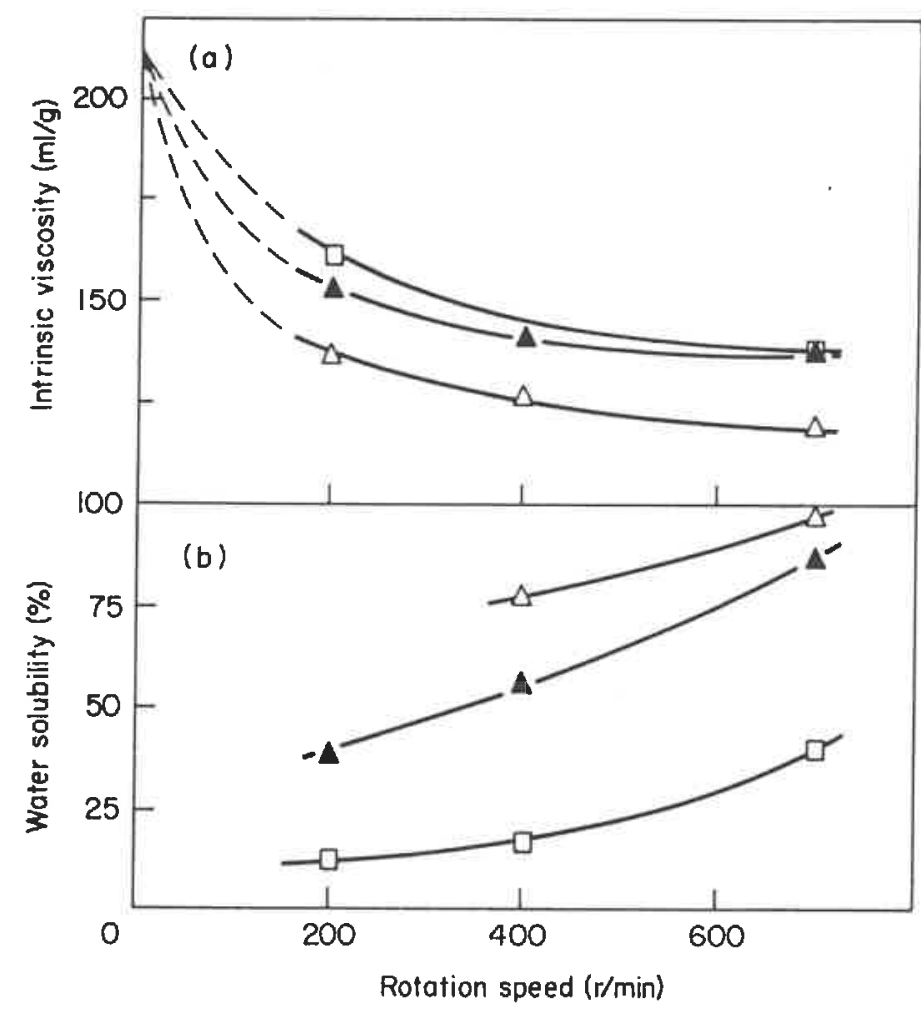

FIGURE 4. (a) Variation of the intrinsic viscosity at $160^{\circ} \mathrm{C}$ and (b) the water solubility at $140^{\circ} \mathrm{C}$ of processed starch with varying rotation speed and different rotation times: $\square, 10 \mathrm{~s} ; \Delta, 20 \mathrm{~s} ; \Delta, 40 \mathrm{~s}$.

\section{Functional properties}

At the capillary exit, the melted starch suddenly expands, giving rise to an internal lattice structure, formed by a solid starch film with large air cells, in the range $0.5-5 \mathrm{~mm}$. This feature varied greatly with the samples. Maximal area expansion ratio was about $6 \cdot 8$, but this parameter was not studied systematically because it is not directly connected 
with the macromolecular structure of the product. The expansion of a sample submitted to a well-defined pretreatment varied greatly (from 1.36 to 5.44 ) when the velocity through the capillary was suddenly increased by increasing the down velocity of the inner piston (the shear rate varying from $20 / \mathrm{s}$ to about 300/s) (Fig. 5). This may be related to the pseudoplastic, non-Newtonian behaviour of the molten starch. Its viscosity decreased when the shear rate increased ${ }^{24}$. At low shear rates, the viscosity is very high and the vapour bubbles cannot expand. By increasing the shear rate, the viscosity is greatly decreased and the expansion becomes possible. Consequently, it is possible to obtain materials with the same degree of macromolecular transformation (related to the thermomechanical treatment) but different expansion.

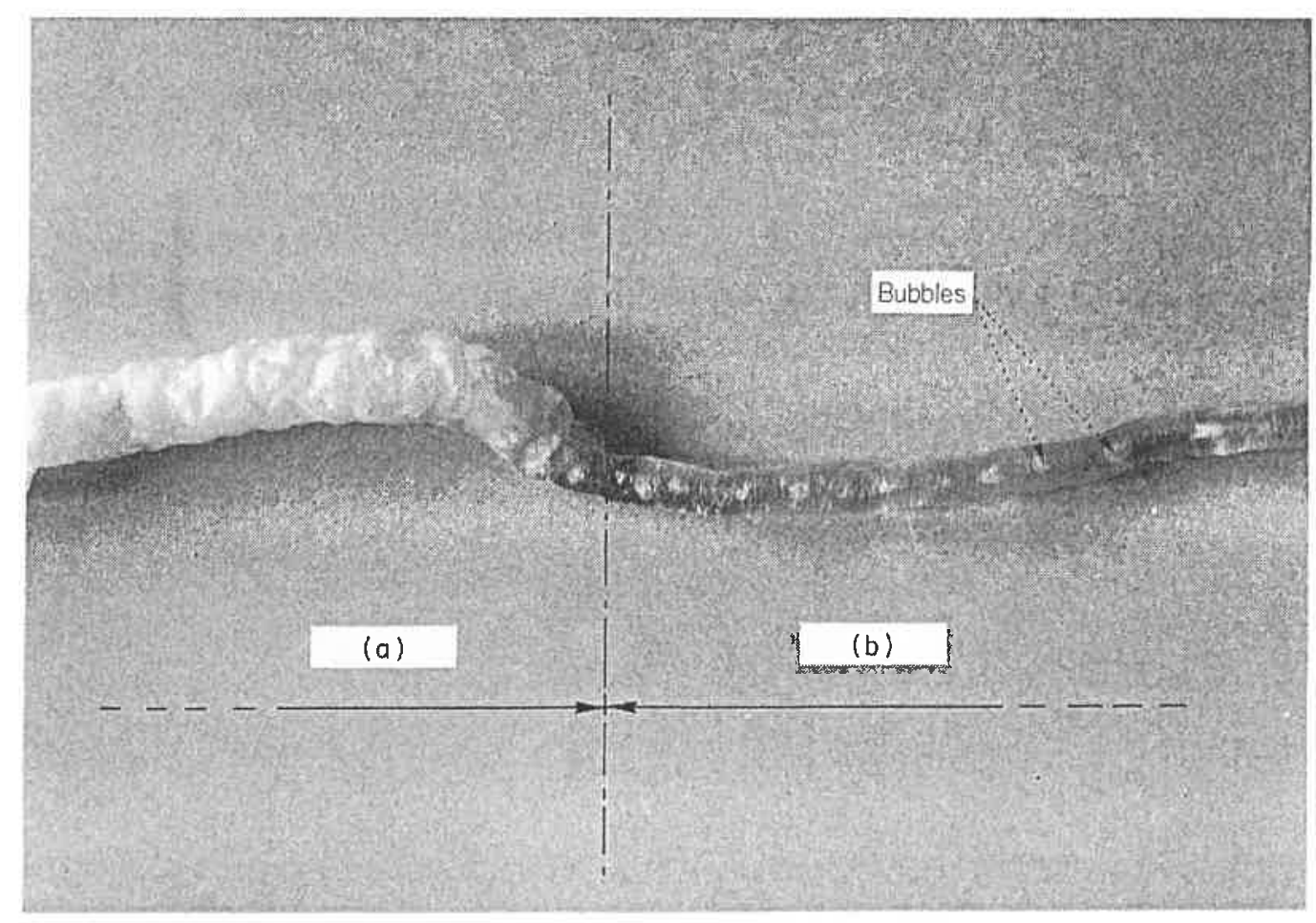

FIGURE 5. Sample subjected to the same thermomechanical treatment and extruded through the capillary at two different shear rates, (a) $300 / \mathrm{s}$ and (b) $20 / \mathrm{s}$, the difference in expansion results is only from the pseudoplastic behaviour.

Ground, processed starches (particle size, 100-125 $\mu \mathrm{m}$ ) were partly water soluble. Water solubility increased with rotation time, rotation speed and with temperature. 'Mild' treatment conditions gave products with low solubility (10-15\%) whereas more severe conditions led to almost completely $(95 \%)$ soluble products (Fig. 4).

Water solubility increased (from 10 to $95 \%$ ) and intrinsic viscosity decreased (from 210 to $110 \mathrm{ml} / \mathrm{g}$ ) when the severity of the thermomechanical treatment was increased. These two parameters are, at different levels, representative of the macromolecular degradation of the processed starch. 


\section{Theoretical Approach}

It is clear that the behaviour of the starch in the Rheoplast is very complex. There is very little published information about the transformation of starch granules to molten mass at low water content. The classical phenomenon of gelatinisation at $60-80^{\circ} \mathrm{C}$ cannot be involved in our experiments with the Rheoplast, as the amount of water is limited $(<25 \%)$ and too low for gelatinisation to occur. Under these conditions, the transformation of starch occurs by melting of the crystallites ${ }^{25,26}$, leading to a molten phase, the existence of which was shown by investigations with a twin-screw extruder with a horizontally split barrel ${ }^{17}$. Furthermore, the rheological properties of the molten mass can change during the process. However, a simplified theoretical approach may be used to define general parameters able to characterise the intensity of the process.

We hypothesise that two successive steps occur during the process, 1 , the melting of starch in the Couette zone of the Rheoplast and 2, the shearing of the molten material, which will provide the macromolecular degradation by input of mechanical energy. Both thermal and mechanical energy are transmitted to the material in the Rheoplast. Initially, this energy contributes to the heating and melting of the material, i.e. disrupting the starch granule and transforming the starch into a homogeneous gelified mass. Then, the mechanical energy provided to this melted material will lead to product degradation by breaking some bonds along macromolecular chains.

There is, at present, a lack of rheological data concerning starch at low moisture contents. Capillary measurements carried out on the Rheoplast at different temperatures, different moisture contents and with dies of different diameters (L/D ratios in the range of $4-17)^{24}$, as well as previous papers published in the literature ${ }^{27}$, suggest the occurrence of a pseudoplastic behaviour. During the process, this rheological behaviour is assumed to remain constant.

\section{Melting process}

At the start of the experiment, the Couette shearing zone is filled with native starch and the inner piston is moved by rotation. A thin layer of molten material (layer radius, $\delta$ ) appears along the piston and its thickness will gradually increase by input of mechanical energy due to shear. Another thin layer, $\delta_{0}$, also appears at the barrel wall but its rate of increase, due only to the thermal conduction, is much slower, it is assumed that it remains constant during the melting (Fig. 6).

We suppose that the increase of the melted layer $\delta$ is controlled by heat transfer at the solid/melt interface in the same way as the melting of a thermoplastic material in a single screw extruder ${ }^{28}$ (the symbols used in the following equations are defined in the Appendix to this paper).

or

$$
q_{1}=q_{\mathrm{s}}+\rho_{\mathrm{s}} \Delta H(\mathrm{~d} \delta / \mathrm{d} t)
$$

$$
\left.k_{1} \frac{\partial T}{\partial r}\right|_{r=\delta}=\left.k_{\mathrm{s}} \frac{\partial T}{\partial r}\right|_{r=\delta}+\rho_{\mathrm{s}} \Delta H(\mathrm{~d} \delta / \mathrm{d} t)
$$

The following assumptions are made: 


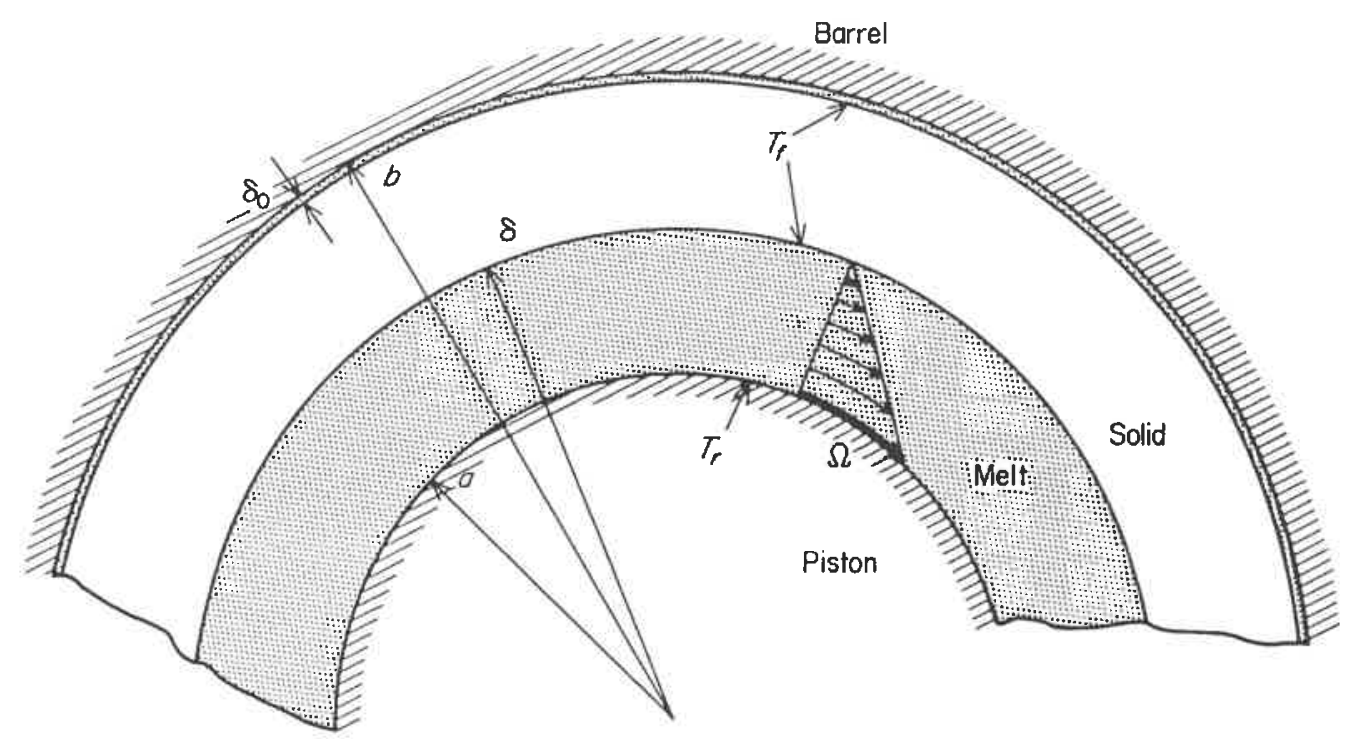

FIGURE 6. Diagram of the melting zone, for symbols see Appendix.

1. The pseudoplastic behaviour of the melted starch is described by a power-law ${ }^{24,27}$

$$
\eta=K|\dot{\gamma}|^{m-1}
$$

2. The temperature is steady $((\partial T / \partial t)=0,(\partial T / \partial \theta)=0)$ and uniform following the $z$-axis $(\partial T / \partial z)=0)$.

3. The boundary conditions are as follows, the temperature of the molten material is controlled by the barrel temperature and only the layer radius increases: $T(a)=T_{R}$ (constant barrel temperature), $T(\delta)=T_{f}$ (melting temperature).

4. The temperature profile in the solid is obtained by considering a succession of steady states. Only the first term of the series solution ${ }^{29}$ is considered.

We can then obtain the heat flows in the melt and in the solid at the interface, in the melt:

$$
q_{1}=k_{1} \frac{T_{R}-T_{f}}{\delta \log \delta / a}+K \Omega^{m+1}[2 / m]^{m-1} \frac{\delta}{\left[(\delta / a)^{2 / m}-1\right]^{m}}\left[2 / m \frac{1}{1-(\delta / a)^{2 / m}}+\frac{1}{\log \delta / a}\right]
$$

in the solid:

$$
q_{\mathrm{s}}=4 k_{s} \frac{T_{f}-T_{\mathrm{i}}}{b-\delta} \exp \left[\frac{-\pi^{2} k_{s}}{\rho_{s} C_{s}} \frac{t}{(b-\delta)^{2}}\right]
$$

Substituting equations (4) and (5) into equation (1) leads to:

$$
\begin{aligned}
\frac{\mathrm{d} \delta}{\mathrm{d} t}=\frac{1}{\rho_{s} \Delta H}\left\{\frac{k_{1}\left(T_{R}-T_{f}\right)}{\delta \log \delta / a}+K \Omega^{m+1}[2 / m]^{m-1} \frac{\delta}{\left[(\delta / a)^{2 / m}-1\right]^{m}}\right. \\
\left.\quad\left[2 / m \frac{1}{1-(\delta / a)^{2 / m}}+\frac{1}{\log \delta / a}\right]-\frac{4 \mathrm{k}_{\mathrm{s}}\left(T_{f}-T_{i}\right)}{b-\delta} \exp \left[\frac{-\pi^{2} k_{\mathrm{s}}}{\rho_{s} C_{s}} \frac{t}{(b-\delta)^{2}}\right]\right\}
\end{aligned}
$$

This equation is solved iteratively starting from an initial value $\delta_{0}$. It allows computation of the time, $t_{f}$, necessary for the melting of a layer with a thickness, $b-a$ (the depth of 
the Couette zone). The variation of the melting time with the regulation temperature is shown in Fig. 7. The theoretical values (between 3 and $15 \mathrm{~s}$ ) are very close to those observed experimentally.

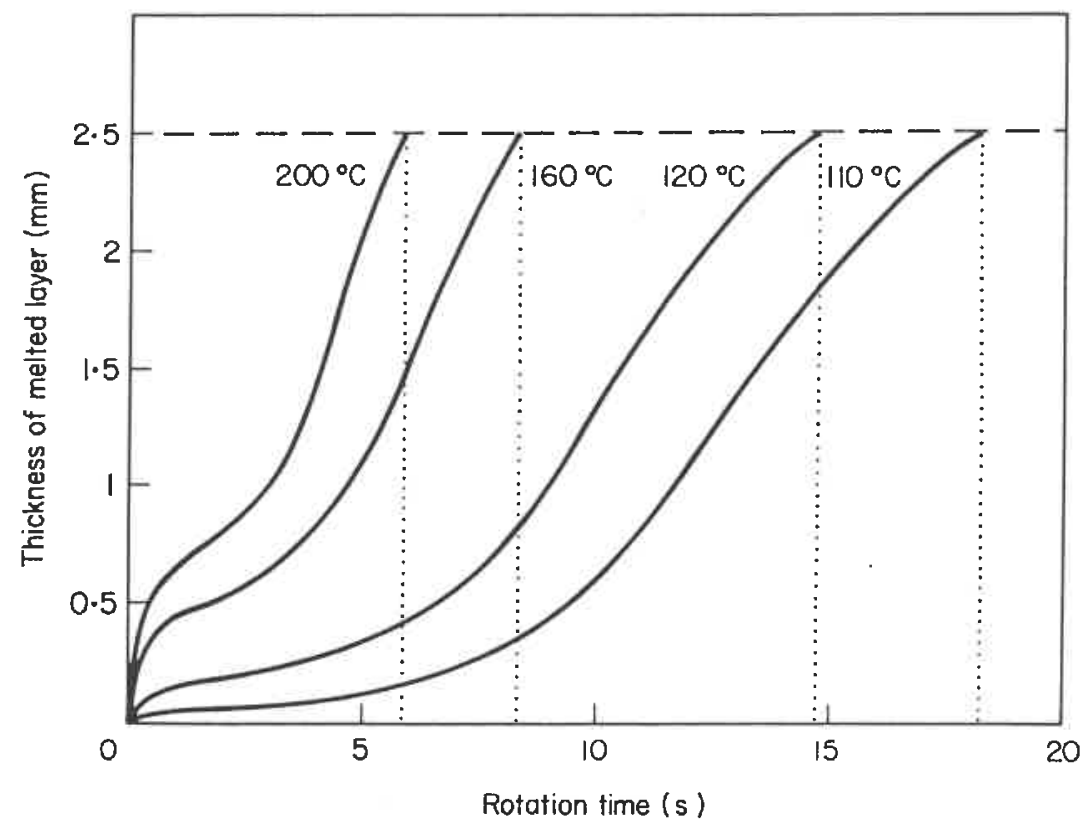

FIGURE 7. Variation of the thickness of the melted layer at $200 \mathrm{r} / \mathrm{min}$ at varying rotation times and temperatures.

\section{Mechanical energy}

Once the material is melted, it is subjected to a shear rate defined by

$$
\dot{\gamma}(r)=\frac{2 \Omega}{m\left[1-(b / a)^{2 / m}\right]}\left[\frac{b}{r}\right]^{2 / m}
$$

Locally, the mechanical energy dissipated per unit of time is given by

$$
\begin{gathered}
\dot{w}(r)=K|\dot{\gamma}(r)|^{m+1} \\
\dot{w}(r)=K\left[\frac{2 \Omega}{m\left[1-(b / a)^{2 / m}\right]}\right]^{m+1}\left[\frac{b}{r}\right]^{2(1+1 / m)}
\end{gathered}
$$

During the rotation, the mean quantity of energy provided per unit volume of the molten material is

or

$$
\dot{W}=\frac{\int_{a}^{b} \int_{0}^{h} 2 \pi r \dot{w}(r) d r d z}{\pi\left(b^{2}-a^{2}\right) h} \Delta t
$$

$$
\dot{W}=\frac{m K b^{2}}{(b / a)^{2}-1}\left[\frac{2}{m}\right]^{m+1} \frac{1}{\left[b^{2 / m}-a^{2 / m}\right]^{m}} \Omega^{m+1} \Delta t
$$

where $\Delta t=t_{\mathrm{r}}-t_{\mathrm{f}}$ is the effective time during which the molten starch was sheared. 
The mechanical energy $\dot{W}$ is proportional to the shearing time and to the rotation rate to the power $m+1$. The following parameters must be defined to calculate this mechanical energy: 1 , geometrical parameters, $a, b ; 2$, operating conditions, $\Omega, T_{i}, T_{\mathrm{r}}$; 3 , physical characteristics of the material, $\rho_{s}, k_{s}, k_{1}, \Delta H, T_{f}, C_{s}, K, m$.

The physical characteristics of the material are the most difficult to define. The following values have been taken from the few papers on this subject ${ }^{1,24,27,30,31}$. $\rho_{s}=1500 \mathrm{~kg} / \mathrm{m}^{3} ; \quad \Delta H=15 \mathrm{~kJ} / \mathrm{kg} ; \quad T_{f}=110^{\circ} \mathrm{C} ; \quad C_{s}=1.7 \mathrm{~kJ} / \mathrm{kg} /{ }^{\circ} \mathrm{C} ; \quad k_{s}=0.2$ $\mathrm{W} /{ }^{\circ} \mathrm{C} / \mathrm{m} ; k_{1}=0.2 \mathrm{~W} /{ }^{\circ} \mathrm{C} / \mathrm{m} ; K=20,000 \mathrm{~Pa} \mathrm{~s}{ }^{m} ; m=0.3$.

\section{Discussion}

Starch samples processed by the Rheoplast present the same type of modifications as those obtained by extrusion-cooking: change of crystalline type from A- to E- and V-types ${ }^{5}$, decrease of molecular weights ${ }^{15,18}$ as shown by GPC and intrinsic viscosity measurements, appearance of solubility $(95 \%)$ and area expansion (two- to six-fold) ${ }^{3}$. The levels of degradation are close to those obtained with single and twin-screw extruders: variations in intrinsic viscosity in the range of $110-210 \mathrm{ml} / \mathrm{g}$ were previously measured on extruded starches. Solubilised macromolecules are mainly responsible for determining the overall properties of extruded starches in solution: either water solubility or intrinsic viscosity may be used to quantify the level of macromolecular degradation of processed $\operatorname{starch}^{32}$. Physical conditions in the Rheoplast mimic the conditions in an extruder, by producing similar values for temperature, length and intensity of shearing. However, the Rheoplast differs from classical capillary or slit rheometers ${ }^{33,34}$ by the shearing applied previously to the viscosity measurement in the die. All the results demonstrate that the macromolecular degradation increases with the shear rate, the shearing time and the temperature. However, to compare the intensity of treatments whose physical parameters are very different, a thermomechanical analysis of the melting and shearing process in the Rheoplast is necessary, in order to define a

Table I. Melting time $\left(t_{f}\right)$, effective shearing time $(\Delta t)$, mechanical energy input $(W)$, intrinsic viscosity $([\eta])$, and water solubility $(W S)$ for different thermomechanical treatments of maize starch (temperature $T_{R}$, rotation speed $\Omega$ and rotation time $t_{r}$ )

\begin{tabular}{|c|c|c|c|c|c|c|c|}
\hline \multicolumn{3}{|c|}{ Processing conditions } & \multicolumn{3}{|c|}{ Computed results } & \multicolumn{2}{|c|}{$\begin{array}{l}\text { Measured } \\
\text { results }\end{array}$} \\
\hline $\begin{array}{c}T_{R} \\
\left({ }^{\circ} \mathrm{C}\right)\end{array}$ & $\begin{array}{c}\Omega \\
(\mathrm{r} / \mathrm{min})\end{array}$ & $\begin{array}{l}t_{r} \\
(\mathrm{~s})\end{array}$ & $\begin{array}{l}t_{f} \\
(\mathrm{~s})\end{array}$ & $\begin{array}{l}\Delta t \\
(\mathrm{~s})\end{array}$ & $\begin{array}{c}\dot{W} \\
\left(\mathrm{~J} / \mathrm{m}^{3}\right)\end{array}$ & $\underset{(\mathrm{ml} / \mathrm{g})}{[\mathrm{\eta}]}$ & $\begin{array}{l}W S \\
(\%)\end{array}$ \\
\hline 160 & 700 & 40 & $2 \cdot 8$ & $38 \cdot 2$ & $10 \cdot 4810^{8}$ & 118 & 96 \\
\hline 160 & 700 & 20 & $2 \cdot 8$ & $18 \cdot 2$ & $4.9910^{8}$ & 137 & 92 \\
\hline 160 & 700 & 10 & $2 \cdot 8$ & $8 \cdot 2$ & $2 \cdot 2510^{8}$ & 138 & 59 \\
\hline 160 & 400 & 20 & $5 \cdot 1$ & $14 \cdot 9$ & $1.9710^{8}$ & 140 & 59 \\
\hline 160 & 700 & 5 & $2 \cdot 8$ & $3 \cdot 2$ & $0.8810^{8}$ & 176 & 25 \\
\hline 180 & 200 & 20 & $6 \cdot 9$ & $13 \cdot 1$ & $0.7110^{8}$ & 151 & 35 \\
\hline 160 & 200 & 20 & $8 \cdot 3$ & $11 \cdot 7$ & $0.6310^{8}$ & 152 & 55 \\
\hline 140 & 200 & 20 & $10 \cdot 6$ & $9 \cdot 4$ & $0.5110^{8}$ & 171 & 38 \\
\hline
\end{tabular}


global parameter which is capable of quantifying the intensity of the treatment. Physical modelling of this thermomechanical process leads to two characteristic parameters, the melting time, $t_{f}$, and the mechanical energy, $\dot{W}$. Computed values of these parameters are shown in Table I for different treatments. There is a wide variation range (about 50) of the mechanical energy received by the material between the extremes of treatments imposed. As a consequence, the intensity of the different treatments can now be classified (in Table I the treatments are arranged in decreasing values of $\dot{W}$ ). Rotation rate appears to be the main parameter, whereas temperature is of secondary importance.

The variation of the intrinsic viscosity with the mechanical energy input is shown in Fig. 8. Despite a scatter in the values due to the heterogeneity of the samples analysed and the approximations made in analysing the rheological data, a relationship between the variations of the two parameters clearly appears.

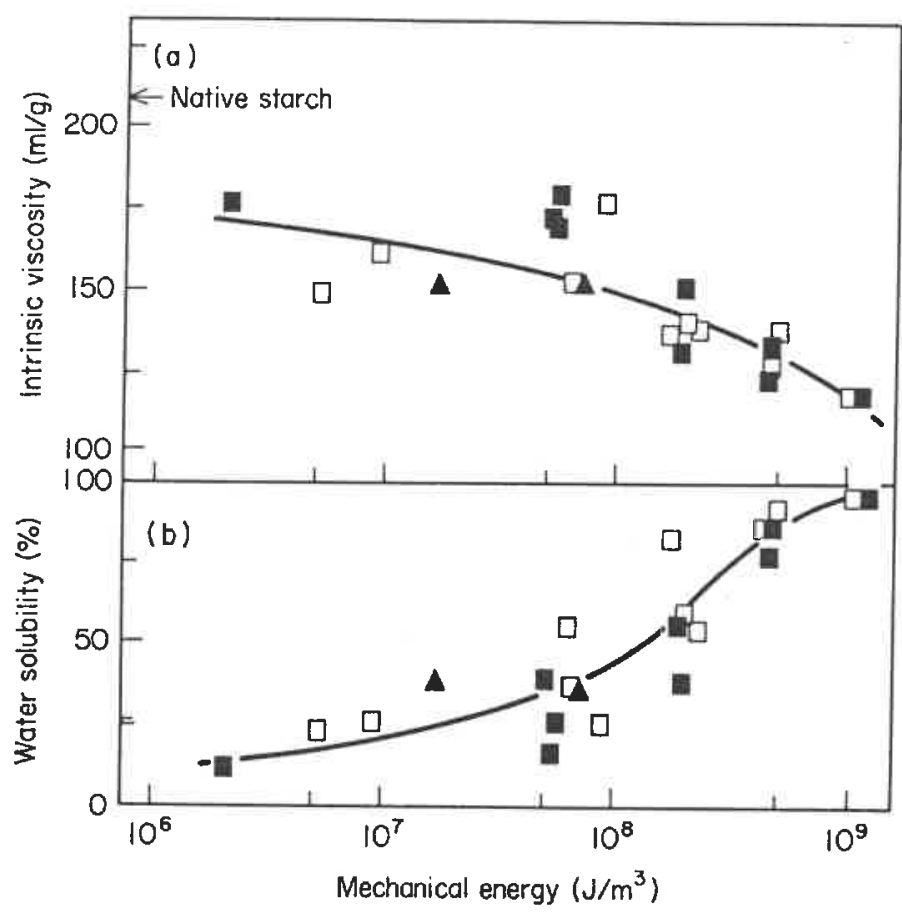

FIGURE 8. (a) Variation of intrinsic viscosity and (b) variation in the water solubility of processed starch with mechanical energy input. $\square, 140^{\circ} \mathrm{C} ; \square, 160^{\circ} \mathrm{C} ; \Delta, 180^{\circ} \mathrm{C}$.

The same result is observed concerning the water solubility (Fig. 8), the solubility increases with the energy dissipated in the material and a quasi-soluble product can be obtained when the energy is greater than $10^{9} \mathrm{~J} / \mathrm{m}^{3}$. Ollku $\mathrm{u}^{4}$ who also observed the same type of relationship was, however, unable to quantify the intensity of the treatment. Similarly, Meuser et al. ${ }^{20}$ observed that the viscosity decreased and the solubility increased by increasing the 'specific mechanical energy' provided to wheat starch. All these observations agree with the studies of stress-induced polymer reactions, recently reviewed by Porter and Casale ${ }^{35}$. 


\section{Conclusion}

A newly developed rheometer was used to study the starch transformation. This permitted the study of the influence of the different thermomechanical parameters. The starch degradation is a direct function of the mechanical energy received during the treatment. This energy can be evaluated from rheological data and processing conditions in order to define the intensity of the treatment and to classify different thermomechanical treatments. These results should be useful for the modelling of extrusion-cooking; after computing the flow of molten starch in the various extruder screw elements, it should be possible to predict the level of starch transformation, by using the experimental curves relating the quantity of mechanical energy and a starch characteristic (such as solubility or intrinsic viscosity).

This study was supported by Grant 81-C-0170 awarded by the Delegation Générale à la Recherche Scientifique et Technique, France. The authors thank Dr A. Buléon for the X-ray analysis and A. Stephant and P. Williams for their skilful technical assistance.

\section{References}

1. Harper, J. M. Crit. Rev. Food Sci. Nutr. 11 (1979) 155-215.

2. Linko, P., Colonna, P. and Mercier, C. Adv. Cereal Sci. Technol. 4 (1981) 145-235.

3. Mercier, C. and Feillet, P. Cereal Chem. 52 (1975) 283-297.

4. Charbonniere, R., Duprat, P. and Guilbot, A. Cereal Sci. Today 18 (1973) 286.

5. Mercier, C., Charbonniere, R., Gallant, D. and Guilbot, A. in 'Polysaccharides in Food', (J. M. V. Blanshard and J. R. Mitchell, eds.), Butterworths, London, (1979) pp 152-170.

6. Mercier, C., Charbonniere, R., Grebaut, J. and De La Gueriviere, J. F. Cereal Chem. 57 (1980) 4-9.

7. Conway, H. F., Lancaster, K. B. and Bookwalter, C. N. Food Eng. 41 (1968) 102-105.

8. Conway, H. F. Food Prod. Dev. 4 (1971) 27-29.

9. Conway, H. F. Food Prod. Dev. 5 (1971) 14-16.

10. Anderson, R. A., Conway, H. F., Pfeifer, V. F. and Griffin, E. L. Cereal Sci. Today, 14 (1969) 4-7, 11-12.

11. Anderson, R. A., Conway, H. F., Pfeifer, V. F. and Griffin, E. L. Cereal Sci. Today, 14 (1969) 372-375, 381.

12. Anderson, R. A., Conway, H. F. and Peplinski, A. J. Stärke 22 (1970) 130-135.

13. Mottern, H. H., Spadaro, J. J. and Gallo, A. S. Food Technol. 23 (1969) 169-171.

14. Olkku, J. in 'Developments in Food Preservation' (S. Thorne, ed.), Applied Science, London (1981).

15. Colonna, P. and Mercier, C., Carbohydr. Polym. 3 (1983) 87-108.

16. Davidson, V. J., Paton, D., Diosady, L. L. and Larocque, G. J. Food Sci. 49 (1984) 453-458.

17. Colonna, P., Melcion, J. P., Vergnes, B. and Mercier, C. J. Cereal Sci. 1 (1983) 115-125.

18. Colonna, P., Doublier, J. L., Melcion, J. P., De Monredon, F. and Mercier, C. Cereal Chem. 61 (1984) $538-543$.

19. Aguilera, J. A. and Kosikowski, F. V. J. Food Sci. 41 (1976) 647-651.

20. Meuser, F., Van Lengerich, B. and Kohler, F. Stärke 34 (1982) 366-372.

21. Villemaire, J. P. and Agassant, J. F. in 'Intérrelations between Processing, Structure and Properties of Polymeric Materials' (J. C. Seferis and P. S. Theocaris, eds.), Elsevier, Amsterdam, (1984) pp 271-278.

22. Villemaire, J. P. and Agassant, J. F. Polym. Proc. Eng. 3 (1984) 223-232.

23. Colonna, P., Biton, V. and Mercier, C. Carbohydr. Res. 137 (1985) 151-166.

24. Vergnes, B. Villemaire, J. P., Colonna, P. and Tayeb, J. Cah. Groupe Fr. Etud. Rhéol. (in press).

25. Donovan, J. W. Biopolymers 18 (1979) 263-275.

26. Colonna, P. and Mercier, C., Phytochem. 24 (1985) 1667-1674.

27. Yacu, W. A. in Thermal Processing and Quality of Food' (P. Zeuthen et al., eds.), Elsevier, Amsterdam (1983) pp 62-78. 
28. Tadmor, Z. and Klein, I. 'Engineering Principles of Plasticating Extrusion', Van Nostrand Rheinhold, New York (1970).

29. Carslaw, H. S. and Jaeger, J. C. 'Conduction of Heat in Solids', Oxford University Press (1959).

30. Stevens, D. J. and Elton, G. A. H. Stärke 23 (1971) 8-11.

31. Harper, J. M. 'Extrusion of Foods', Vol. 1, CRC Press, Boca Raton (1981).

32. Doublier, J. L., Colonna, P. and Mercier, C. Cereal Chem. 63 (1986) 240-246.

33. Van Wazer, J. R., Lyons, J. W., Kim, K. Y. and Colwell, R. E. 'Viscosity and Flow Measurements, A Laboratory Handbook of Rheology', Interscience, New York (1963).

34. Remsen, C. H. and Clark, J. P. J. Food Proc. Eng. 2 (1978) 39-64.

35. Porter, R. S. and Casale, A. Polym. Eng. Sci. 25 (1983) 129-156.

\section{Appendix}

The symbols used in this paper are defined as follows:

$a$ inner piston radius (m)

$b \quad$ barrel radius $(\mathrm{m})$

$c_{s} \quad$ specific heat $\left(\mathrm{J} / \mathrm{kg} /{ }^{\circ} \mathrm{C}\right)$

$h$ height of the Couette zone $(\mathrm{m})$

$k_{1} \quad$ melt thermal conductivity $\left(\mathrm{W} /{ }^{\circ} \mathrm{C} / \mathrm{m}\right)$

$k_{s} \quad$ solid thermal conductivity $\left(\mathrm{W} /{ }^{\circ} \mathrm{C} / \mathrm{m}\right)$

$K \quad$ consistency $\left(\mathrm{Pa} \mathrm{s}^{m}\right)$

$m \quad$ pseudoplasticity index

$q_{1} \quad$ heat flow in the melt $\left(\mathrm{W} / \mathrm{m}^{2}\right)$

$q_{s}$ heat flow in the solid $\left(\mathrm{W} / \mathrm{m}^{2}\right)$

$r, \theta, z$ cylindrical co-ordinate system

$t$ time (s)

$t_{\mathrm{f}} \quad$ melting time (s)

$t_{\mathrm{r}} \quad$ rotation time (s)

$T_{\mathrm{P}} \quad$ melting temperature $\left({ }^{\circ} \mathrm{C}\right)$

$T_{1} \quad$ initial temperature $\left({ }^{\circ} \mathrm{C}\right)$

$T_{R} \quad$ barrel wall temperature $\left({ }^{\circ} \mathrm{C}\right)$

$W$ mechanical energy per unit volume $\left(\mathrm{J} / \mathrm{m}^{3}\right)$

$\delta \quad$ melt layer radius (m)

$\delta_{0} \quad$ initial melt layer radius (m)

$\Delta t \quad$ effective shearing time (s)

$\eta \quad$ viscosity (Pa s)

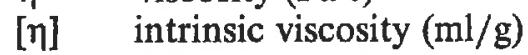

$\rho_{s} \quad$ density $\left(\mathrm{kg} / \mathrm{m}^{3}\right)$

$\Omega$ rotation speed, $(\mathrm{r} / \mathrm{min})$ 